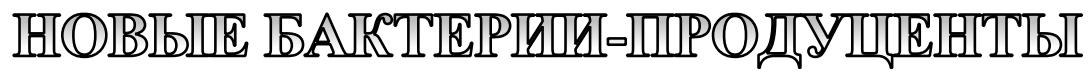

OCMIOIDOTIEIKTOPHULIXX BELULECTB,

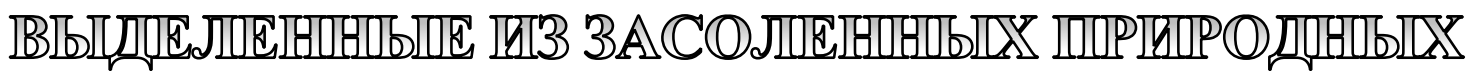

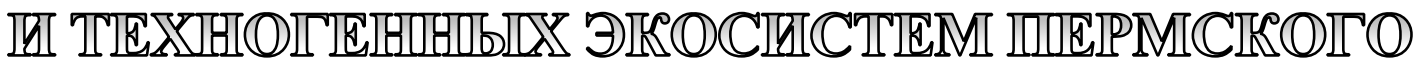

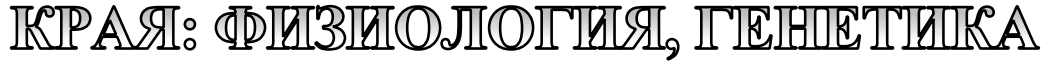

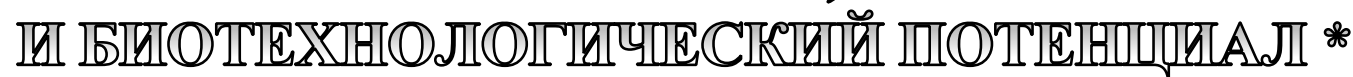

Л.Н. Ананьина, Институт экологии и генетики микроорганизмов УрО РАН А.А. Горбунов, Институт технической химии УрО РАН

А.А. Пьянкова, Институт экологии и генетики микроорганизмов УрО РАН

Е.А. Шестакова, Институт экологии и генетики микроорганизмов УрО РАН

А.В. Назаров, Институт экологии и генетики микроорганизмов УрО РАН

Д.О. Егорова, Институт экологии и генетики микроорганизмов УрО РАН

А.О. Воронина, Институт экологии и генетики микроорганизмов УрО РАН

Проведен скрининг галофильных и галотолерантных бактерий, изолированных из биоценозов района промышленных разработок Верхнекамского месторождения калийно-магниевых солей (Пермский край), на способность синтезировать биотехнологически значимый осмопротектор эктоин. Для исследования были отобраны штаммы представителей родов Halomonas и Chromohalobacter семейства Halomonadaceae класса Gammaproteobacteria, a также штаммы бактерий, принадлежащих родам Arthrobacter и Rhodococcus класcа Actinobacteria. В ходе исследований методом спектроскопии ЯМР ${ }^{1} \mathrm{H}$ охарактеризована доля эктоина по отношению к другим соединениям, накапливаемым клетками в условиях высокого осмотического давления. Показано, что в клетках представителей семейства Halomonadaceae преобладал эктоин: его доля составляла, в зависимости от штамма, 64,0-78,1\%.

Осуществлен структурно-функциональный анализ генов, кодирующих ферменты синтеза эктоина, в геномах бактерий родов Halomonas, Chromohalobacter, Cobetia, Kushneria, Halotalea и Salinicola семейства Halomonadaceae, депонированных в публичной базе данных Национального центра биотехнологической информации США (NCBI). Разработан и апробирован протокол амплификации еct-генов у бактерий исследованных таксономических групп.

Ключевые слова: галофильные и галотолерантные бактерии, осмопротекторные вещества, эктоин.

\footnotetext{
* Исследование выполнено при финансовой поддержке РФФИ и Министерства образования и науки Пермского края, проект № 17-44-590178, и в рамках государственного задания, номер госрегистрации темы AAAA-A19-119112290008-4.
} 
В настоящее время особое внимание уделяется изучению молекулярных механизмов адаптации бактерий к жизни в экстремальных условиях. Большинство галофильных и галотолерантных прокариот поддерживают осмотический баланс, накапливая внутри клетки за счет транспорта из внешней среды или синтеза de novo низкомолекулярные органические соединения - осмопротекторы («совместимые вещества»). Осмопротекторы являются высокорастворимыми полярными веществами разных классов: аминокислотами, их производными, пептидами; полиолами, сахарами и их производными; бетаинами; эктоинами $[17,18]$.

Наиболее распространенным осмопротектором гетеротрофных эубактерий является эктоин $[5,17]$. Высокая совместимость с биологическими системами, отсутствие токсичности, стабилизирующие макромолекулы (ферменты, ДНК и РНК, мембраны) свойства и клеткозащитное действие делают эктоин многообещающим кандидатом для применения в различных биотехнологических целях. В настоящее время практическое применение эктоин находит в косметической промышленности (в частности, в средствах по уходу за кожей). Кроме того, особый интерес представляет направление использования эктоина в фармацевтической промышленности и медицине - для консервации биологического материала и увеличения сроков сохранности и эффективности лекарственных препаратов [13]. В настоящее время охарактеризованы ферментные и генетические системы биосинтеза эктоина у отдельных штаммов родов Brevibacterium, Streptomyces, Halomonas, $\quad$ Chromohalo- bacter, Ectothiorhodospira, Methylobacter, Methylophaga, Marinococcus, Bacillus и Halobacillus [4, 6, 7, 10-12, 14, 15, 20]. До сих пор остаются неизученными или малоизученными процессы биосинтеза эктоина широко используемых в области биоремедиации окружающей среды и процессах утилизации стойких органических загрязнителей актинобактерий родов Arthrobacter и Rhodococcus [3, 8]. В связи с вышеизложенным представляется актуальным поиск и изучение новых бактерий, способных к гиперпродукции эктоина.

Целью настоящего исследования явился скрининг галотолерантных бактерий-деструкторов моно- и полиароматических углеводородов актинобактерий родов Rhodococcus и Arthrobacter, а также умеренногалофильных протеобактерий родов Halomonas и Chromohalobacter ceмейства Halomonadaceae из лабораторной коллекции ЛММБ «ИЭГМ УрО РАН», выделенных ранее из высокоминерализованных экотопов (солеотвалы) и прилегающих к ним засоленных почв района промышленной разработки Верхнекамского соленосного бассейна, на способность синтезировать биотехнологически значимый осмопротектор - эктоин.

\section{Методы исследования}

Активно растущие бактериальные культуры поддерживали пассажами на плотную богатую среду Раймонда [2], содержащую $5 \%$ хлорида натрия, методом Коха (с отдельных колоний) с последующим инкубированием в термостате ТС-1/80 СПУ (Россия) при температуре $28^{\circ} \mathrm{C}$. Изучение кинетики роста штаммов в зависимости от концентрации хлорида натрия (табл. 1,2$)$ про-

Таблица 1

Характеристика исследованных штаммов родов Arthrobacter и Rhodococcus

\begin{tabular}{|c|c|c|c|c|}
\hline \multirow[t]{2}{*}{ Штамм } & \multirow{2}{*}{$\begin{array}{c}\text { Филогенетически } \\
\text { близкородственный штамм (уровень } \\
\text { сходства фррагмента гена 16S PHK, \%) }\end{array}$} & \multirow[t]{2}{*}{ Показатель } & \multicolumn{2}{|c|}{$\begin{array}{c}\text { Концентрация } \mathrm{NaCl} \text { в среде } \\
\text { культивирования, \% }\end{array}$} \\
\hline & & & Без $\mathrm{NaCl}$ & 6 \\
\hline SMB32 & Arthrobacter nicotianae DSM $20123^{\top}(99,5)$ & \multirow{3}{*}{$\begin{array}{c}\text { ОП } \\
\text { Дло макс./ } \\
\text { Куительность } \\
\text { культивирования, ч }\end{array}$} & $1,2 / 17$ & $1,3 / 20$ \\
\hline SMB37 & Rhodococcus artemisiae YIM 65754 $(99,05)$ & & $0,4 / 23$ & $0,25 / 48$ \\
\hline SMB38 & Rhodococcus jostii IFO $16295^{\top}(98,7)$ & & $0,7 / 27$ & $0,3 / 27$ \\
\hline
\end{tabular}

Примечание - рост культуры оценивался путем измерения оптической плотности среды культивирования (исходная ОП ${ }_{540}=0,07-0,11$ ). 
Таблица 2

Характеристика исследованных штаммов семейства Halomonadaceae

\begin{tabular}{|c|c|c|c|c|c|c|c|c|}
\hline \multirow[b]{2}{*}{ Штамм } & \multirow{2}{*}{$\begin{array}{c}\text { Филогенетически } \\
\text { близкородствен- } \\
\text { ный штамм } \\
\text { (уровень } \\
\text { сходства } \\
\text { фрагмента гена } \\
\text { 16S PHК, \%) }\end{array}$} & \multirow[b]{2}{*}{ Показатель } & \multicolumn{6}{|c|}{ Концентрация $\mathrm{NaCl}$ в среде культивирования, \% } \\
\hline & & & 1 & 5 & 10 & 15 & 20 & 25 \\
\hline SMB31 & $\begin{array}{l}\text { H. taeanensis } \\
\text { BH539 }(99,8)\end{array}$ & \multirow{2}{*}{$\begin{array}{c}\text { ОП } \\
\text { Дло макс./ } \\
\text { культивироность } \\
\text { сунания, ч }\end{array}$} & $0,79 / 24$ & $1,07 / 24$ & $1,04 / 30$ & $0,89 / 80$ & $0,59 / 98$ & $0,11 / 98$ \\
\hline N1 & $\begin{array}{c}\text { C. japonicus } 43^{\top} \\
(99,92)\end{array}$ & & $0,07 / 167$ & $0,8 / 22$ & $0,94 / 28$ & $0,7 / 84$ & $0,64 / 167$ & $0,07 / 167$ \\
\hline
\end{tabular}

Примечание - рост культуры оценивался путем измерения оптической плотности среды культивирования (исходная $\mathrm{OП}_{540}=0,07-0,11$ ).

водили при культивировании в 100 мл минеральной среды Раймонда [2], содержащей 1 г/л глюкозы (ОАО «Дальхимфарм», Россия), в колбах объёмом 250 мл на орбитальном шейкере УВМТ-12-250 («Элион», Россия) при 100 об/мин. Оптическую плотность измеряли на спектрофотометре BioSpec-mini TCC-240A (Shimadzu corporation, Япония) при 540 нм в кювете с длиной оптического пути 1 см. Контроль чистоты бактериальных культур проводился разными способами: микроскопированием клеток методом фазового контраста, рассевом бактериальных культур на плотные богатые среды с последующим визуальным учетом морфологии колоний.

Для исследования «совместимых веществ» (осмопротекторов) бактериальную культуру выращивали в минеральной среде Раймонда с глюкозой, содержащей 5 или $6 \%$ хлорида натрия, при $28^{\circ} \mathrm{C}$ до фазы замедленного роста. С целью исследования регуляции биосинтеза эктоина бактериальные культуры выращивали в минеральной среде Раймонда с глюкозой при разных значениях солености среды и температуры до фазы замедленного роста. Экстракцию органических соединений из клеток проводили, следуя процедуре, разработанной Bernard с соавторами [4]. 20 мкл каждого образца анализировали изократической высокоэффективной жидкостной хроматографией (ВЭЖХ) на прибоpe Shimadzu prominence LC-20AD (Shimadzu corporation, Япония), снабженном UV/VIS-детектором

CPD-20A
(Shimadzu corporation, Япония) и колонкой Сепарон SGX $100 \mathrm{NH}_{2}$, 4,6х150 мм, 5 мкм (Dr. Maisch GmbH, Германия), согласно методике, описанной в статье [9].

Идентификацию соединений проводили при сравнении времени удерживания с коммерческим препаратом эктоина (Fluka, Германия). Дополнительно состав этанольных экстрактов клеток исследовали методом спектроскопии ЯМР ${ }^{1} \mathrm{H}$. Для этого высушенный осадок растворяли в 0,5 мл $\mathrm{D}_{2} \mathrm{O}$ (ООО «Астрахим», Россия) и записывали спектр при $30^{\circ} \mathrm{C}$ на приборе Bruker Avance Neo 400 (Bruker Corporation, США), при частоте 400 МГц. Идентификацию сигналов в спектре проводили сравнением с литературными данными, со спектрами аутентичных образцов и путем добавления веществ к пробе.

Все эксперименты были выполнены в трехкратной повторности. Полученные данные обрабатывали с использованием программы Microsoft Excel 2007.

Геномную ДНК выделяли методом щелочного лизиса целых клеток [19]. Амплификацию ect-генов на матрице ДНК исследуемых штаммов и электрофоретическое разделение фрагментов проводили согласно протоколу, описанному в статье [1]. Секвенирование генов осуществляли с помощью использованных для амплификации праймеров, Big Dye Terminator Ready Reaction Kit v3.1 («Thermo Fisher Scientific», США) на приборе Genetic Analyzer 3500xl («Thermo Fisher Scientific», США), следуя инструкциям фирмы-произ- 
водителя в лаборатории молекулярной биологии и генетики при кафедре ботаники и генетики растений ПГНИУ.

В публичной базе данных Национального центра биотехнологической информации США (NCBI) (https://www.ncbi.nlm.nih.gov) осуществлен поиск и структурный анализ генетических локусов, кодирующих ферменты синтеза эктоина и гидроксиэктоина, в геномах умеренногалофильных бактерий семейства Halomonadaceae.

\section{Результаты и обсуждение \\ Для исследования были} отобраны 12 умеренногалофильных штаммов представителей родов Halomonas и Chromohalobacter семейства Halomonadaceae класса Gammaproteobacteria и 6 галотолерантных штаммов бактерий, принадлежащих родам Arthrobacter и Rhodococcus класса Actinobacteria, из рабочей коллекции микроорганизмов Лаборатории молекулярной микробиологии и биотехнологии «Института экологии и генетики микроорганизмов УрО РАН». Предварительный скрининг штаммов на способность к синтезу эктоина в условиях высокой солености среды методом ВЭЖХ показал, что исследованные культуры накапливали эктоин. Для последующего изучения совместимых соединений методом спектроскопии ЯМР ${ }^{1} \mathrm{H}$ из каждой таксономической группы были отобраны штаммы, характеризующиеся наибольшим значением оптической плотности на стационарной фазе роста и образующие гомогенную суспензию клеток при росте в минеральной среде с глюкозой: Halomonas sp. SMB31, Chromohalobacter sp. N1, Arthrobacter sp. SMB32, Rhodococcus spp. SMB37 и
SMB38. Исследование кинетики роста отобранных штаммов показало, что галотолерантные штаммы, за исключением штамма Arthrobacter sp. SMB32, характеризовались низкими значениями максимальной оптической плотности и скорости роста в присутствии повышенных концентраций хлорида натрия (см. табл. 1, 2).

Охарактеризована доля эктоина от суммы всех веществ клетки с помощью отношения интегральных интенсивностей сигналов протонов эктоина к интегральной интенсивности сигналов всех протонов в спектрах ЯМР ${ }^{1} \mathrm{H}$. Установлено, что эктоин был преобладающим соединением в этанольных экстрактах клеток штаммов семейства Halomonadaceae, в то время как в клетках бактерий класса Actinobacteria доминировали другие вещества (табл. 3). При этом метод ВЭЖХ обнаружил более высокую чувствительность, выявив эктоин в следовом количестве в этанольных экстрактах клеток штамма Arthrobacter sp. SMB32, в то время как в спектре ЯМР ${ }^{1} \mathrm{H}$ сигналы эктоина не были обнаружены.

Для дальнейшего исследования влияния условий культивирования на биосинтез эктоина были отобраны штаммы-представители семейства Halomonadaceae. Увеличение концентрации хлорида натрия в среде культивирования с 5 до 15\% приводило к снижению доли дополнительных соединений в этанольных клеточных экстрактах штаммов Halomonas sp. SMB31 и Chromohalobacter sp. N1 с 21,9\% до 17,7\% и с $36,0 \%$ до $10,9 \%$, соответственно (табл. 4). Показано, что при возрастании солености среды культивирования в клетках накапливался гидроксиэктоин. Установлено, что увеличение температуры культивирования с $28^{\circ} \mathrm{C}$ до $40^{\circ} \mathrm{C}$ приво-

Таблицча 3

Отношение интегральных интенсивностей сигналов протонов эктоина к интегральной интенсивности сигналов всех протонов в спектрах ЯМР 1Н этанольных экстрактов, \%

\begin{tabular}{|c|c|c|c|c|c|}
\hline Штамм & $\begin{array}{c}\text { Arthrobacter sp. } \\
\text { SMB32* }\end{array}$ & $\begin{array}{c}\text { Rhodococcus sp. } \\
\text { SMB37* }\end{array}$ & $\begin{array}{c}\text { Rhodococcus sp. } \\
\text { SMB38* }\end{array}$ & $\begin{array}{c}\text { Halomonas sp. } \\
\text { SMB31** }\end{array}$ & $\begin{array}{c}\text { Chromohalo- } \\
\text { bacter sp. N1** }\end{array}$ \\
\hline Эктоин, \% & 0,0 & 17,2 & 5,6 & 78,1 & 64,0 \\
\hline
\end{tabular}

Примечание: * - при культивировании в минеральной среде Раймонда в присутствии 6\% $\mathrm{NaCl}$, ** - при культивировании в минеральной среде Раймонда в присутствии 5\% $\mathrm{NaCl}$. 
Таблица 4

Отношение интегральных интенсивностей сигналов протонов эктоина и гидроксиэктоина к интегральной интенсивности сигналов всех протонов в спектрах ЯМР ${ }^{1} \mathrm{H}$ этанольных экстрактов, \%

\begin{tabular}{|c|c|c|c|c|c|}
\hline \multirow[b]{2}{*}{ Штамм } & \multicolumn{2}{|c|}{ Условия культивирования } & \multirow[b]{2}{*}{ Эктоин, \% } & \multirow{2}{*}{$\begin{array}{l}\text { Гидрокси- } \\
\text { эктоин, \% }\end{array}$} & \multirow{2}{*}{$\begin{array}{c}\text { Остальные } \\
\text { вещества, \% }\end{array}$} \\
\hline & $\mathrm{NaCl}, \%$ & $\begin{array}{l}\text { Температура, } \\
\text { oC }\end{array}$ & & & \\
\hline \multirow{5}{*}{$\begin{array}{l}\text { Halomonas sp. } \\
\text { SMB31 }\end{array}$} & 5 & 28 & 78,1 & 0,0 & 21,9 \\
\hline & 10 & 28 & 82,5 & 2,2 & 15,3 \\
\hline & 15 & 28 & 67,9 & 14,4 & 17,7 \\
\hline & 5 & 37 & 72,9 & 1,6 & 25,5 \\
\hline & 5 & 40 & 63,6 & 2,0 & 34,4 \\
\hline \multirow{5}{*}{$\begin{array}{l}\text { Chromohalo- } \\
\text { bacter sp. N1 }\end{array}$} & 5 & 28 & 64,0 & 0,0 & 36,0 \\
\hline & 10 & 28 & 75,5 & 0,1 & 24,4 \\
\hline & 15 & 28 & 79,3 & 9,8 & 10,9 \\
\hline & 5 & 37 & 34,8 & 0,0 & 65,2 \\
\hline & 5 & 40 & 21,3 & 0,0 & 78,7 \\
\hline
\end{tabular}

дило к снижению доли эктоина и увеличению доли других органических соединений в клеточных экстрактах исследованных штаммов (см. табл. 4). Наиболее высокая доля дополнительных соединений $(78,7 \%)$ была отмечена у штамма Chromohalobacter sp. N1. Осуществлен поиск генетических локусов, кодирующих ферменты синтеза эктоина, в геномах бактерий, депонированных в публичной базе данных NCBI (США). В анализ были включены нуклеотидные последовательности 33 штаммов умеренногалофильных бактерий семейства Halomonadaceae представителей родов
Halomonas, Chromohalobacter, Cobetia, Kushneria, Halotalea и Salinicola. Установлено, что в геномах исследованных бактерий ген ectA, кодирующий L-2,4-диаминобутиратацетилтрансферазу, и гены есtВ и ectC, детерминирующие диаминобутиратаминотрансферазу и эктоинсинтазу, соответственно, расположены в указанной последовательности. Ген, кодирующий эктоингидроксилазу, ectD [9], не входит в ect-оперон и расположен в другом локусе хромосомы (табл. 5).

С целью оптимизации условий полимеразной цепной реакции для амплифика-

Организация генов, кодирующих ферменты синтеза эктоина и гидроксиэктоина, у представителей семейства Halomonadaceae

\begin{tabular}{|c|c|c|c|c|}
\hline Род & \multicolumn{4}{|c|}{ Организация есt-генов } \\
\hline & ectA & ectB & ectC & ectD \\
\hline & ectA & ectB & ectC & ectD \\
\hline & ectA & ectB & ectC & ectD \\
\hline Kurborio & ectA & ectB & ectC & ectD \\
\hline & ectA & ectB & ectC & ectD \\
\hline & ectA & ectB & ectC & ectD \\
\hline
\end{tabular}


ции участка ect-оперона на ДНК матрице типовых штаммов валидных видов родов Salinicola, Chromohalobacter и Halomonas семейства Halomonadaceae ранее сконструированными праймерами [1] провели несколько реакций, отличающихся составом реакционной смеси по количеству праймеров. Так, на ДНК-матрице большинства исследованных штаммов, за исключением S. halophilus CECT5903 ${ }^{\mathrm{T}}$ и S. socius $\mathrm{SMB}^{\mathrm{T}}$, продукт ожидаемой длины был амплифицирован при 10 пкмоль праймеров. Увеличение количества олигонуклеотидов в ПЦР смеси с 10 до 50 пкмоль привело к синтезу искомого фрагмента на матрице ДНК штаммов $S$. socius $\mathrm{SMB}^{\mathrm{T}}{ }^{\mathrm{n}}$ и $\mathrm{S}$. halophilus CECT5903 ${ }^{\mathrm{T}}$ (рис.). На матрице ДНК штамма $S$. socius $\mathrm{SMB}^{\mathrm{T}}{ }^{\mathrm{T}}$ был синтезирован неспецифический фрагмент размером около 200 п.н.

Для подтверждения амплификации фрагмента ect-оперона была определена нуклеотидная последовательность ПЦРпродуктов всех тестируемых штаммов. Последующий сравнительный анализ полученных нуклеотидных последовательностей с депонированными в публичных ба- зах ect-генами с помощью программы Blastn (http://blast.ncbi.nlm.nih.gov/Blast.cgi) выявил их гомологию с есt-генами бактерий семейства Halomonadaceae (табл. 6). В ходе исследования впервые определены нуклеотидные последовательности ect-генов типовых штаммов видов C. beijerinckii, C. japonicus и C. canadensis.

\section{Заключение}

Проведенные исследования расширяют представления о механизмах осмоадаптации эубактерий семейства Halomonadaceae, a также родов Arthrobacter и Rhodococcus. Полученные результаты могут указывать на высокую консервативность механизмов адаптации к высокой осмолярности среды у умеренногалофильных бактерий семейства Halomonadaceae. Обобщая полученные в ходе исследования, а также представленные в литературе данные, можно заключить, что преобладающим осмопротекторным соединением бактерий семейства Halomonadaceae является эктоин; между тем исследованные галотолерантные представители родов Arthrobacter

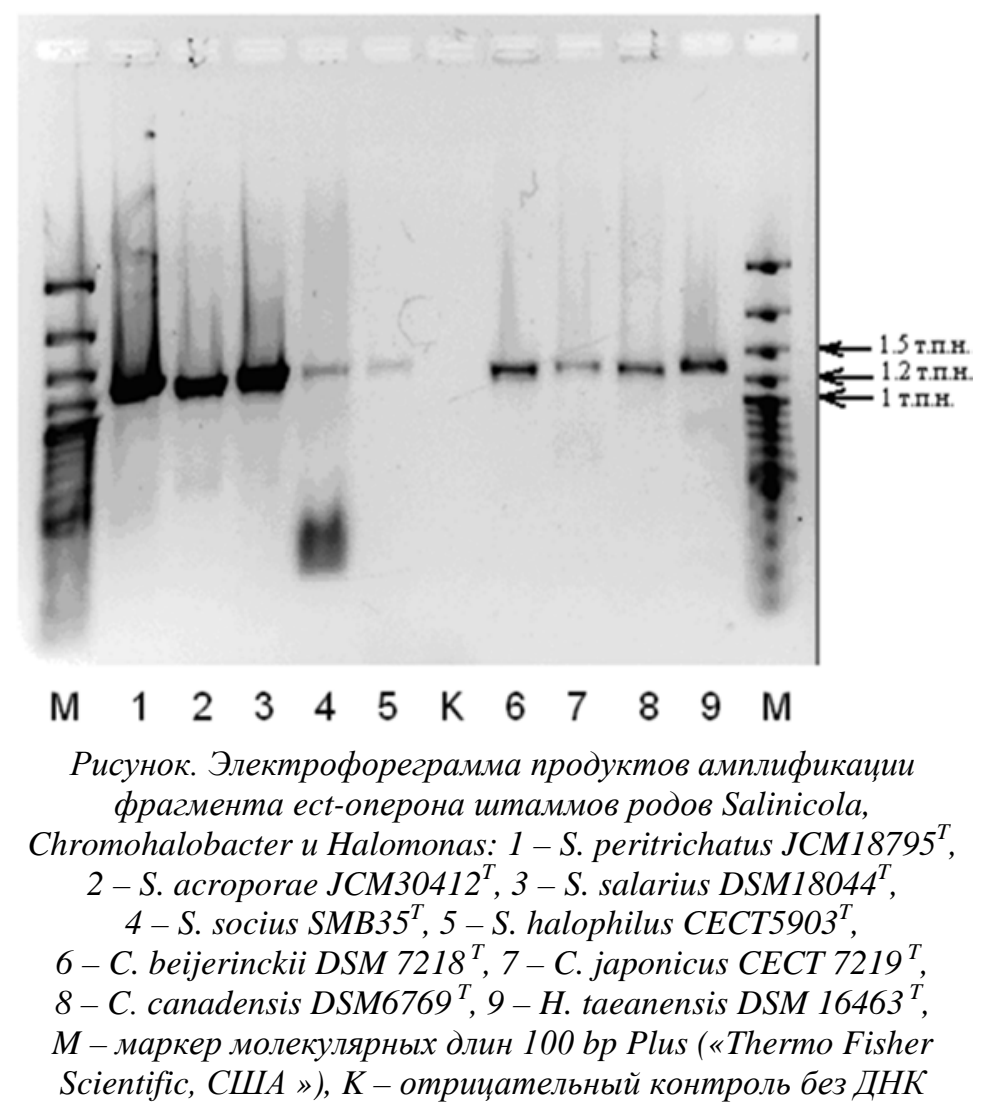


Таблица 6

Результаты филогенетического анализа амплифицированных фрагментов есt-оперона

\begin{tabular}{|c|c|c|c|}
\hline Штамм & $\begin{array}{c}\text { Штамм с максимальным уровнем } \\
\text { сходства анализируемого фрагмента } \\
\text { ДНК }\end{array}$ & $\begin{array}{c}\text { Сходство } \\
\text { фрагмента ДНК, } \\
\% \\
\end{array}$ & $\begin{array}{c}\text { Количество } \\
\text { анализированных } \\
\text { нуклеотидов }\end{array}$ \\
\hline $\begin{array}{l}\text { S. peritrichatus } \\
\text { JCM18795 }\end{array}$ & S. peritrichatus JCM18795' & 100,00 & 860 \\
\hline S. acroporae JCM30412 ${ }^{\top}$ & S. acroporae LMG $28587^{\top}$ & 100,00 & 783 \\
\hline S. salarius DSM18044 ${ }^{\top}$ & S. salarius DSM18044 & 100,00 & 770 \\
\hline S. socius SMB35 & S. socius SMB35 & 100,00 & 754 \\
\hline S. halophilus CECT5903' & S. halophilus CECT5903' & 100,00 & 860 \\
\hline C. beijerinckii DSM $7218^{T^{*}}$ & C. canadaensis USBA855 & 90,76 & 833 \\
\hline $\begin{array}{c}\text { C. japonicus CECT } \\
7219^{T^{*}}\end{array}$ & C. japonicus CJ & 95,30 & 745 \\
\hline $\begin{array}{c}\text { C. canadensis } \\
\text { DSM6769T }^{*}\end{array}$ & C. canadaensis USBA855 & 95,03 & 745 \\
\hline $\begin{array}{c}\text { H. taeanensis DSM } \\
16463^{\top}\end{array}$ & H. taeanensis НВ539т & 100,00 & 833 \\
\hline
\end{tabular}

Примечание: * - нуклеотидные последовательности типовых штаммов в публичных базах не представлены.

и Rhodococcus класcа Actinobacteria характеризуются низким внутриклеточным количеством эктоина.

Таким образом, в качестве перспективных объектов для биотехнологического синтеза эктоина могут рассматриваться бактерии семейства Halomonadaceae. При изучении аспектов регуляции биосинтеза эктоина у бакте- рий семейства Halomonadaceae установлено, что накопление эктоина в клетках исследованных культур индуцируется повышением концентрации хлорида натрия в среде культивирования и зависит от температуры. Полученные данные могут служить основой для биотехнологического производства эктоина умеренногалофильными бактериями.

\section{Библиографический список}

1. Ананьина Л.Н., Шестакова Е.А., Пьянкова А.А., Плотникова Е.Г. Дизайн системы олигонуклеотидов и оптимизация условий амплификации есt-генов бактерий рода Salinicola семейства Halomonadaceae // Вестник Пермского Университета. Серия биология. - 2017. - В. 3. - С. 297-303.

2. Розанова Е.П., Назина Т.Н. Углеводородокисляющие бактерии и их активность в нефтяных пластах // Микробиология. - 1982. - Т. 51. - №. 2. - С. 342-348.

3. Alvarez H.M., Silva R.A., Cesari A.C., Zamit A.L., Peressutti S.R., Reichelt R., Keller U., Malkus U., Rasch C., Maskow T., Mayer F., Steinbchel A. Physiological and morphological responses of the soil bacterium Rhodococcus opacus strain PD630 to water stress // FEMS Microbiology Ecology. - 2004. Vol. 50. - № 2. - P. 75-86.

4. Bernard T., Jebbar M., Rassouli Y., HimidiKabbab S., Hamelin J., Blanco C. Ectoine accumulation and osmotic regulation in Brevibacterium linens // The Journal of General Microbiology. - 1993. - Vol. 139. - P. 129-136.

5. Calderon M.I., Vargas C., Rojo F., Iglesias-Guerra F., Csonka L.N., Ventosa A., Nieto J.J. Complex regulation of the synthesis of the compatible solute ectoine in the halophilic bacterium Chromohalobacter salexigens DSM 3043 ${ }^{\mathrm{T}} / /$ Microbiology. - 2004. - Vol. 150. - P. 3051-3063.

6. Canovas D., Vargas C., Calderon M.I., Ventosa A., Nieto J.J. Characterization of the genes for the biosynthesis of the compatible solute ectoine in the moderately halophilic bacterium Halomonas elongata DSM 3043 // Systematic and Applied Microbiology. - 1998. - Vol. 21. - № 4. - P. 487-497.

7. Canovas D., Vargas C., Iglesias-Guerra F., Csonka L.N, Rhodes D., Ventosa A., Nieto J.J. Isolation and characterization of salt sensitive mutants of the moderate halophile Halomonas elongata and cloning of the ectoine synthesis gene // The Journal of Biological Chemistry. - 1997. - Vol. 272. - № 41. - P. 25794-25801.

8. Cappelletti M., Fedi S., Zampolli J., Di Canito A., D'Ursi P., Orro A., Viti C., Milanesi L., Zannoni D., Di Gennaro $P$. Phenotype microarray analysis may unravel genetic determinants of the stress response by Rhodococcus aetherivorans BCP1 and Rhodococcus opacus R7 // Research in Microbiology. - 2016. Vol. 167. - № 9-10. - P. 766-773.

9. García-Estepa R., Argandoña M., Reina-Bueno M., Capote N., Iglesias-Guerra F., Nieto J.J., Vargas C. The ectD gene, which is involved in the synthesis of the compatible solute hydroxyectoine, is essential for 
thermoprotection of the halophilic bacterium Chromohalobacter salexigens // Journal of Bacteriology. 2006. - Vol. 188. - P. 3774-3784.

10. Kuhlmann A.U., Hoffmann T., Bursy J., Jebbar M., Bremer E. Ectoine and hydroxyectoine as protectants against osmotic and cold stress: uptake through the SigB-controlled betaine-choline- carnitine transporter-type carrier EctT from Virgibacillus pantothenticus // Journal of Bacteriology. - 2011. - Vol. 193. - № 18. - P. 4699-4708.

11. Kuhlmann A.U., Bremer E. Osmotically regu lated synthesis of the compatible solute ectoine in Bacillus pasteurii and related Bacillus spp. // Applied and Environmental Microbiology. - 2002. - Vol. 68. - № 2. P. 772-783.

12. Kuhlmann A.U., Bursy J., Gimpel S., Hoffmann T., Bremer E. Synthesis of the compatible solute ectoine in Virgibacillus pantothenticus is triggered by high salinity and low growth temperature / A.U. Kuhlmann, // Applied and Environmental Microbiology. - 2008. - Vol. 74. - № 14. - P. 4560-4563.

13. Lentzen G., Schwarz T. Extremolytes: Natural compounds from extremophiles for versatile applications // Applied and Environmental Microbiology. - 2006. - Vol. 72. - № 4. - P. 623-634.

14. Louis P., Galinski E.A. Characterization of genes for the biosynthesis of the compatible solute ectoine from Marinococcus halophilus and osmoregulated expression in Escherichia coli // Microbiology (UK). - 1997. Vol. 143. - № 4. - P. 1141-1149.

15. Malin G., Lapidot A. Induction of synthesis tetrahydropyrimidine derivatives in Streptomyces strain and their effect on Escherichia coli in response to osmotic and heat stress // Journal of Bacteriology. - 1996. Vol. 178. - № 2. - P. 385-395.

16. Peters R., Galinski E.A., Truper H.G. The biosynthesis of ectoine // FEMS Microbiology Letters. - 1990.Vol. 71. - № 1-2. - P. 157-162.

17. Roberts M.F. Organic compatible solutes of halotolerant and halophilic microorganisms // Saline systems. 2005. - P. 1-5.

18. Ventosa A., Nieto J., Oren A. Biology of moderately halophilic aerobic bacteria// Microbiology and Molecular Biology Reviews. - 1998. - Vol.62. - № 2. - P. 504-544.

19. Versalovic J., Schneider M., Bruijn F., Lupski J.R. Genomic fingerprinting of bacteria using repetitive sequence-based polymerase chain reaction // Methods in molecular cell biology. - 1994. - Vol. 5. - P. 25-40.

20. Zhao B., Lu W., Yang L., Zhang B., Wang L., Yang S.S. Cloning and characterization of the genes for biosynthesis of the compatible solute ectoine in the moderately halophilic bacterium Halobacillus dabanensis $\mathrm{D} 8^{\mathrm{T}} / /$ Current Microbiology. - 2006. - Vol. 53. - P. 183-188.

\title{
NOVEL BACTERIA-PRODUCERS OF OSMOPROTECTIVE COMPOUNDS ISOLATED FROM SALINIZED NATURAL AND TECHNOGENIC ECOSYSTEMS OF PERM KRAI: PHYSIOLOGY, GENETICS AND BIOTECHNOLOGICAL POTENTIAL
}

\author{
${ }^{1}$ L.N. Ananjina, ${ }^{2}$ A.A. Gorbunov, ${ }^{1}$ A.A. Pyankova, ${ }^{1}$ E.A. Shestakova, \\ ${ }^{1}$ A.V. Nazarov, ${ }^{1}$ D.O. Egorova, ${ }^{1}$ A.O. Voronina \\ ${ }^{I}$ Institute of Ecology and Genetics of Microorganisms UB RAS \\ ${ }_{2}^{2}$ Institute of Technical Chemistry UB RAS
}

Screening of halophilic and halotolerant bacteria isolated from biocenoses of the industrial development area of the Verkhnekamsk potassium-magnesium salt deposit (Perm krai) for the ability to synthesize a biotechnologically significant osmoprotector - ectoine was carried out. For the study, representatives of the genera Halomonas and Chromohalobacter of the Halomonadaceae family of the Gammaproteobacteria class, as well as strains of bacteria belonging to the genera Arthrobacter and Rhodococcus of the Actinobacteria class were selected from the working collection of microorganisms of the Laboratory of Molecular Microbiology and Biotechnology of the «Institute of Ecology and Genetics of Microorganisms (Russian Academy of Science, Ural Branch)». In the course of ${ }^{1} \mathrm{H}$ NMR spectroscopy studies, ectoine was shown to predominate in the cells of the Halomonadaceae family: its proportion, depending on the strain, was $64,0-78,1 \%$. Structural and functional analysis of genes encoding ectoine synthesis enzymes was carried out in the genomes of bacteria of the genera Halomonas, Chromohalobacter, Cobetia, Kushneria, Halotalea and Salinicola of the Halomonadaceae family, deposited in the public database of the National Center for Biotechnological Information 
of the United States (NCBI). A protocol for amplification of the ect-genes in bacteria of the studied taxonomic groups was developed and tested.

Keywords: halophilic and halotolerant bacteria, osmoprotectant solutes, ectoine.

\section{Сведения об авторах}

Ананьина Людмила Николаевна, кандидат биологических наук, научный сотрудник лаборатории молекулярной микробиологии и биотехнологии, Институт экологии и генетики микроорганизмов УрО РАН - филиал Пермского федерального исследовательского центра УрО РАН (ИЭГМ УрО РАН), 614081, г. Пермь, ул. Голева, 13; e-mail: ludaananyina@mail.ru Горбунов Алексей Аркадьевич, кандидат химических наук, старший научный сотрудник лаборатории синтеза активных реагентов, Институт технической химии УрО РАН - филиал Пермского федерального исследовательского центра УрО РАН (ИТХ УрО РАН), 614013, ул. Академика Королева, 3; e-mail: agorbunof@mail.ru

Пьянкова Анна Александровна, инженер лаборатории молекулярной микробиологии и биотехнологии, ИЭГМ УрО РАН; e-mail: annpjankva@mail.ru

Шестакова Елена Анатольевна, инженер лаборатории молекулярной микробиологии и биотехнологии, ИЭГМ УрО РАН; e-mail: sheanton@mail.ru

Назаров Алексей Владимирович, кандидат биологических наук, старший научный сотрудник лаборатории молекулярной микробиологии и биотехнологии, ИЭГМ УрО РАН; e-mail: sheanton@mail.ru

Егорова Дарья Олеговна, кандидат биологических наук, старший научный сотрудник лаборатории молекулярной микробиологии и биотехнологии, ИЭГМ УрО РАН; e-mail: daryao@rambler.ru

Воронина Анна Олеговна, инженер лаборатории молекулярной микробиологии и биотехнологии, ИЭГМ УрО РАН; e-mail: voroninaаo@gmail.com 